\title{
Fabrication of Cellulose Acetate Membrane Using Cyrene as Green Solvent ${ }^{+}$
}

\author{
Yusuf Wibisono ${ }^{1}$, Vira Noviani ${ }^{1}$, Annisa Tri Ramadhani ${ }^{1}$, Amalia Fitry Baruna ${ }^{1}$, Luhur Akbar \\ Devianto ${ }^{2}$ and Akhmad Adi Sulianto ${ }^{2, *}$
}

1 Bioprocess Engineering, Brawijaya University, Malang 65145, Indonesia; y_wibisono@ub.ac.id (Y.W.); viranoviani298@gmail.com (V.N.); annisa3r@gmail.com (A.T.R.); amaliafitrybaruna2712@gmail.com (A.F.B.)

2 Environmental Engineering, Brawijaya University, Malang 65145, Indonesia; luhur.devianto@ub.ac.id (L.A.D.); adi_sulianto@ub.ac.id (A.A.S.)

* Correspondence: Y_Wibisono@ub.ac.id; Tel.: +62-341-571-708

+ Presented at the First International Conference on “Green” Polymer Materials 2020, 5-25 November 2020; Available online: https://cgpm2020.sciforum.net/.

Published: 4 November 2020

\begin{abstract}
Forward osmosis technology is promising molecular separation processes employing osmotic pressure difference of two phases separated by a membrane. Membrane for forward osmosis application has a semipermeable property which selectively passes the certain molecules while reject others. Cellulose triacetate and cellulose acetate are common polymers that are often used in the fabrication of forward osmosis membranes. However, the solvent used in the fabrication of forward osmosis membrane is a toxic organic solvent. Cyrene ${ }^{\mathrm{TM}}\left(\mathrm{C}_{6} \mathrm{H}_{8} \mathrm{O}_{3}\right)$ is a solvent derived from cellulose and is an environmentally friendly solvent because it does not leave sulfur and nitrogen emissions. This work is investigating the fabrication of forward osmosis membranes based on cellulose triacetate and cellulose acetate via phase inversion method, by using Cyrene as solvent. Various composition of the polymers and the green solvent were evaluated. The properties of forward osmosis membranes were characterized by its morphology by scanning electron microscopy and its performance based on water flux and reverse solute flux.
\end{abstract}

Keywords: green membrane; cellulose acetate; $\mathrm{Cyrene}^{\mathrm{TM}}$; forward osmosis; flux; reverse solute flux

\section{Introduction}

Forward osmosis technology is an emerging molecular separation process with various advantages unlike reverse osmosis such as no hydrostatic pressure needed and membrane compaction which would lead to membrane's deformation [1,9]. Forward osmosis uses different osmotic pressure from two phases separated by a membrane. Membrane for forward osmosis application has semipermeable properties that able to selectively passes certain molecules while rejecting others. Forward osmosis technology uses two different solutions, one that has higher osmotic pressure called draw solution (DS) and one that has lower osmotic pressure called feed solution (FS). DS will pull water molecules from FS through a semipermeable membrane until both solutions reach equilibrium osmotic pressure [2].

Common polymers that are often used in the fabrication of forward osmosis membranes are cellulose triacetate and cellulose acetate. CA possesses a hydrophilic property that leads to a high potential for water flux and desalination [3].

The most solvent used in the fabrication of the forward osmosis membrane is a toxic organic solvent, such as NMP, DMF, and DMA. Those solvents create environmental problems as they release emissions which would lead to air pollution. Cyrene ${ }^{\mathrm{TM}}\left(\mathrm{C}_{6} \mathrm{H}_{8} \mathrm{O}_{3}\right)$ is a solvent derived from cellulose 
and is an environmentally friendly solvent because it does not leave sulfur and nitrogen emissions [4]. This work is focusing on fabricating a forward osmosis membrane made by cellulose polymers with an environmentally friendly solvent.

\section{Experiments}

\subsection{Materials}

Cellulose acetate (CA) and Cyrene ${ }^{\mathrm{TM}}$ were obtained from Sigma-Aldrich, Switzerland. All chemicals were more than $99 \%$ pure and were used without further purification.

\subsection{Methods}

The forward osmosis membranes were synthesized using phase inversion method. Various composition of the polymers and the green solvent were assessed. $10 \mathrm{~mL}$ of Cyrene was mixed by required quantity of cellulose acetate according to each composition determined (Table 1). To achieve homogenous paste, the mixture was stirred with the temperature of $85^{\circ} \mathrm{C}$ for $4 \mathrm{~h}$. The membrane solutions were then casted with a casting knife (Elcometer 3580) with $250 \mu \mathrm{m}$ thickness. Vacuum chamber was used to dry the casted member filled with nitrogen. The properties of forward osmosis membranes were characterized by its morphology by scanning electron microscopy and its performance based on water flux and reverse solute flux.

Table 1. Composition of CA-Cyrene Membrane.

\begin{tabular}{ccccc}
\hline & \multicolumn{4}{c}{ Concentration } \\
\cline { 2 - 5 } No. & \multicolumn{2}{c}{ Cellulose Acetate } & \multicolumn{3}{c}{ Cyrene } \\
\cline { 2 - 5 } & $\%$ & gram & $\%$ & mL \\
\hline 1 & 9 & 1.23 & 91 & 10 \\
2 & 12 & 1.7 & 88 & 10 \\
3 & 15 & 2.2 & 85 & 10 \\
\hline
\end{tabular}

\section{Results and Discussion}

\subsection{Effect of Composition on Membrane Morphology}

The cross-section images of CA membranes on three different compositions were investigated with FEI Quanta FEG 650 to observe the morphology of the membrane which can be seen on Figure 1. Using $300 \times$ and $1000 \times$ magnification, it was evidently observed that all the membranes exhibit two layers consists of a dense top layer and semi-porous layer in the middle and bottom of the membranes. The result of this morphology is similar to the membrane structure of CA membrane with acetone and 1,4-dioxane solvent presented in Shang and Shi (2018) with the general similarity of a top dense surface and porous structure in the bottom layer [5]. However, the CA-Cyrene membranes did not possess tear-like voids in the middle sublayer as the CA-acetone membrane did.

The dual layer of the membrane happened due to the phase inversion method, which made the membranes had an asymmetrical structure. The dense top layer was formed due to fast demixing between solvent and non-solvent, thus creating much more compact pores. The semi-porous layers located in the middle and bottom part of the membrane took a little more time to demix because of the formation of the skin layer, thus creating microvoids across the middle and bottom part membrane [6]. 

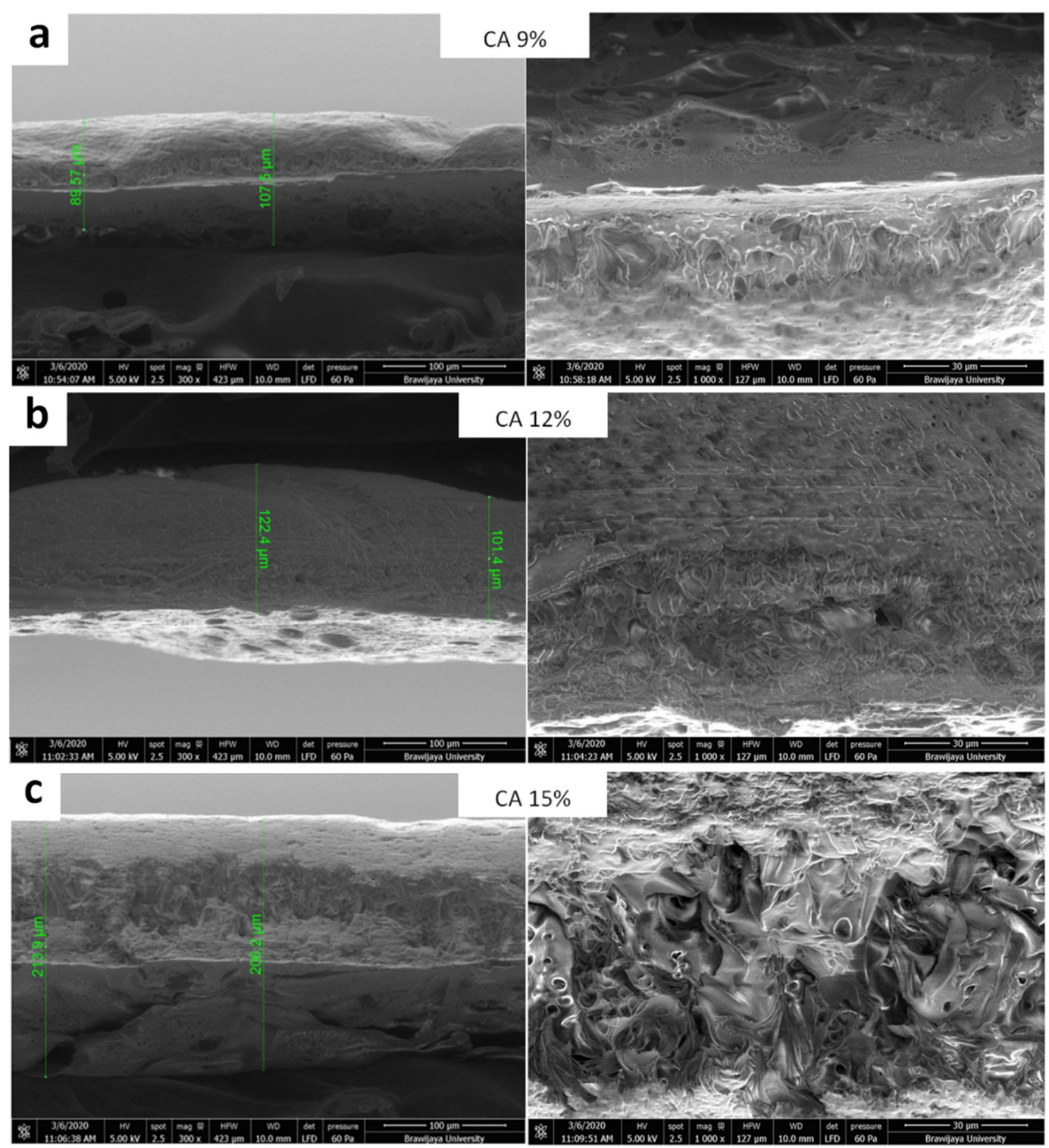

Figure 1. Microscopic cross-section images of CA membranes in 300× and 1000× magnification: (a) Cross-section of $9 \%$ CA membrane; (b) Cross-section of 12\% CA membrane; (c) Cross-section of $15 \%$ CA membrane.

The surface was also investigated with $50 \times$ and $2500 \times$ magnification. As can be seen on Figure 2, the pores on the membranes varied. The membranes possess a rough surfaces with large voids with tiny pores within them. This could caused an increase in pure water flux as the number of pores and their size increase proportionately [7]. The 9\% CA membrane's pore size ranges from $0.578 \mu \mathrm{m}$ to 1.8 $\mu \mathrm{m}$. The $12 \%$ CA membrane has the largest pores, ranges from $3.5 \mu \mathrm{m}$ to $39.94 \mu \mathrm{m}$. Meanwhile, the $15 \%$ CA membrane has the smallest membrane pores that ranges from $0.3430 \mu \mathrm{m}$ to $0.363 \mu \mathrm{m}$. 

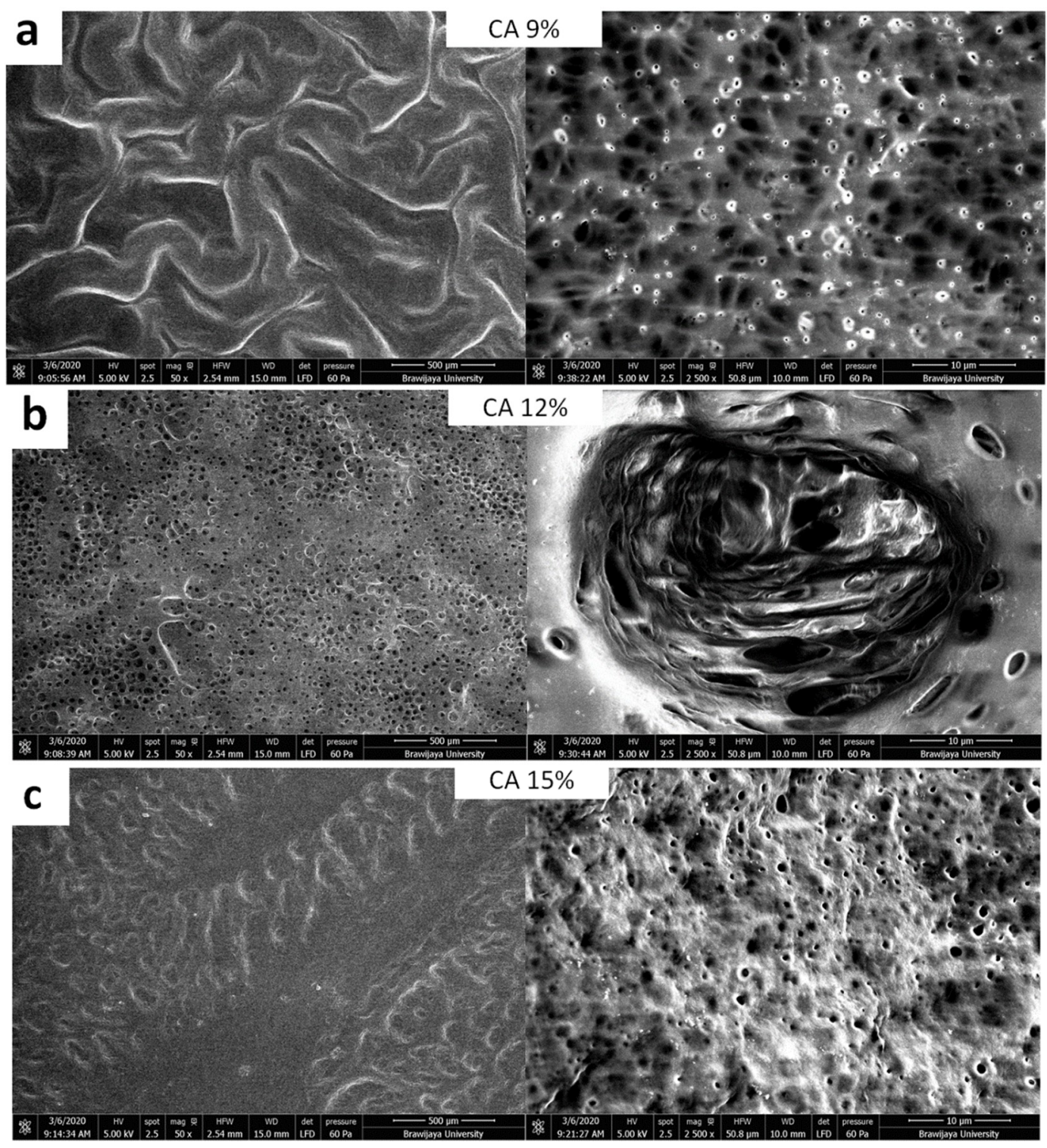

Figure 2. Microscopic surface images of CA membranes in 50× and 2500× magnification: (a) Surface of $9 \%$ CA membrane; (b) Surface of $12 \%$ CA membrane; (c) Surface of $15 \%$ CA membrane.

\subsection{Effect of Composition on Membrane Thickness}

The membranes had shrunk from the initial thickness. The 9\% CA membrane has the most shrinkage as the thickness decreased over $60.585 \%$ from $250 \mu \mathrm{m}$ to $98.535 \mu \mathrm{m}$ on average. On $12 \%$ CA membrane, the thickness decreased over $55.24 \%$ from $250 \mu \mathrm{m}$ to $111.9 \mu \mathrm{m}$ on average. The $15 \%$ CA membrane has the least shrinkage as the thickness decreased over $15.98 \%$ from $250 \mu \mathrm{m}$ to 210.05 $\mu \mathrm{m}$ on average. This thickness decrease is anticipated on FO membrane. Ideal FO membrane is expected to be thin without supporting porous layer and have adequate mechanical properties. The preference of membrane thickness is based on internal concentration polarization (ICP) effect which it gets poorer if it is asymmetric and has a porous layer. Due to ICP occurrence within the membrane, the countermeasures cannot be tackled by hydrodynamic shear forces such as membrane processes with pressure driving forces [8].

\subsection{Water Mass Transport}

The 9\% CA membrane's water flux ranges from $1464,205 \mathrm{Lm}^{-2} \mathrm{~h}^{-1}$ to $1572,136184 \mathrm{Lm}^{-2} \mathrm{~h}^{-1}$, with the average flux of $1523,685744 \mathrm{Lm}^{-2} \mathrm{~h}^{-1}$. The $12 \%$ CA membrane water flux ranges from 1566,026847 $\mathrm{Lm}^{-2} \mathrm{~h}^{-1}$ to $1627,120222 \mathrm{Lm}^{-2} \mathrm{~h}^{-1}$, with the average flux of $1605,228429 \mathrm{Lm}^{-2} \mathrm{~h}^{-1}$. The $15 \% \mathrm{CA}$ 
membrane's water flux ranges from $1521,225039 \mathrm{Lm}^{-2} \mathrm{~h}^{-1}$ to $1568,063293 \mathrm{Lm}^{-2} \mathrm{~h}^{-1}$, with the average flux of $1542,013757 \mathrm{Lm}^{-2} \mathrm{~h}^{-1}$.

\section{Conclusions}

The usage of green solvent cyrene in the fabrication of cellulose acetate membranes has resulted in a membrane with a dense top layer and a semi-porous middle layer with various pore sizes. As the concentration of the polymer increases, the pore size of the membrane tends to be smaller. The CA Cyrene membrane is more suitable when applied to MF technology due to its larger pore size. Further research is needed on how to reduce the pore size of the membrane with pretreatment or additive substances so the membrane could be applied in FO technology.

Conflicts of Interest: The authors declare no conflict of interest.

\section{References}

1. Wibisono, Y.; Bilad, M. Design of forward osmosis system. In Current Trends and Future Developments on (Bio-) Membranes, 1st ed.; Basile, A., Cassano, A., Rastogi, N.K., Ed.; Elsevier: Oxford, UK, 2020, pp.57-83

2. Chung, T.S.; Luo, L.; Wan, C.F.; Cui, Y.; Amy, G. 2. What is next for forward osmosis (FO) and pressure retarded osmosis. Sep. Purif. Technol. 2015, 156, 856-860, doi:1016/j.seppur.2015.10.063.

3. Saraswathi, M.; Rana, D.; Alwarappan, S.; Gowrishankar, S.; Kanimozhi, P.; Nagendran, A. Cellulose acetate ultrafiltration membranes customized with bio-inspired polydopamine coating and in situ immobilization of silver nanoparticles. New J. Chem. 2019, 1-25, doi:10.1039/C8NJ04511A.

4. Sherwood, J.; De bruyn, M.; Constantinou, A.; Moity, L.; McElroy, C.; Farmer, T.; Duncan, T.; Raverty, W.; Hunt, A.J.; Clark, J.H. Dihydrolevoglucosenone $\left(\mathrm{Cyrene}^{\mathrm{TM}}\right)$ as a bio-based alternative for dipolar aprotic solvents. Chem. Commun. 2014, 50, 9650-9652, doi:10.1039/C4CC04133J.

5. Shang, M.; Shi, B. Study on preparation and performances of cellulose acetate forward osmosis membrane. Chem. Pap. 2018, 72, 3159-3167, doi:10.1007/s11696-018-0554-z.

6. Marino, T.; Galiano, F.; Molino, A.; Figoli. A. New frontiers in sustainable membrane preparation: Cyrene $^{\text {TMTM }}$ as green bioderived. J. Membr. Sci. 2019, 580, 224-234, doi:10.1016/j.memsci.2019.03.034.

7. Mohammadi, T.; Saljoughi, E. Effect of production conditions on morphology and permeability of asymmetric cellulose acetate membranes. Desalination 2009, 243, 1-7, doi:10.1016/j.desal.2008.04.010.

8. Phuntsho, S.; Shon, H.; Hong, S.; Lee, S.; Vigneswaran, S.; Kandasamy, J. Fertiliser drawn forward osmosis desalination: the concept, performance and limitations for fertigation. Rev. Environ. Sci. Biotechnol. 2012, 11, 147-168, doi:10.1007/s11157-011-9259-2.

9. Wibisono, Y.; Agung Nugroho, W.; Akbar Devianto, L.; Adi Sulianto, A.; Roil Bilad, M. Microalgae in FoodEnergy-Water Nexus: A Review on Progress of Forward Osmosis Applications. Membranes 2019, 9, 166.

Publisher's Note: MDPI stays neutral with regard to jurisdictional claims in published maps and institutional affiliations.

(C) 2020 by the authors. Submitted for possible open access publication under the terms and conditions of the Creative Commons Attribution (CC BY) license (http://creativecommons.org/licenses/by/4.0/). 